\title{
A arquitetura franciscana sob o ponto de vis- ta de Germain Bazin
}

The franciscan architecture from the point of view of Germain Bazin

\section{Ana Maria Moraes Guzzo*}

*Arquiteta e Urbanista graduada pela Faculdade de Arquitetura e Urbanismo da Universidade Federal do Rio de Janeiro (1991). Mestre em História e Teoria da Arquitetura pelo Programa de Pós-graduação em Arquitetura (PROARQ/ FAU-UFRJ, 1999). Doutoranda do PROARQ/FAU-UFRJ (a partir de março de 2016). Trabalhos publicados relacionados à história da arquitetura, principalmente à arquitetura religiosa.

\section{Resumo}

Este trabalho versa sobre o contexto histórico do Brasil por ocasião da fundação do Instituto do Patrimônio Histórico e Artístico Nacional - IPHAN inicialmente denominado SPHAN, para que se possa tentar entender a denominação dada pelo historiador francês Germain Bazin, aos conventos franciscanos do Nordeste brasileiro: Escola Franciscana do Nordeste. Tal denominação é usada até hoje por vários historiadores, porém pode ser problematizada se levarmos em conta algumas características mencionadas por Bazin como sendo peculiares aos conventos da região citada, já que a literatura nos mostra que essas características aparecem também nos exemplares da região Sudeste. Considerou-se neste artigo também, o desejo da criação e divulgação do nosso patrimônio, no âmbito nacional e internacional, por parte do IPHAN, no momento de sua fundação.

Palavras-chave: Patrimônio cultural. Preservação. Restauração.

\section{Abstract}

This paper analyses the Brazilian historic context during the foundation of the Instituto do Patrimônio Histórico e Artístico Nacional - IPHAN - inicially called SPHAN, in an attempt to understand the denomination given by the French historian Germain Bazin to the Franciscan convents in the northeast of Brazil: Escola Franciscana do Nordeste. This denomination is still being used by several historians, yet it can be challenged if we take into consideration some of the characteristics mentioned by Bazin as being peculiar to the convents of the aforementioned region since the literature shows us that those characteristics can be also found in instances of the southeastern region. This paper has also considered the willingness of IPHAN to create and promote our heritage, on national and international scales, the moment it was founded.

Keywords: Cultural heritage. Preservation. Restauration. 


\section{Introdução}

Este artigo é parte de um capítulo de minha tede doutorado, em que foram estudados os conventos da arquitetura franciscana no Brasil, onde os exemplares da região Nordeste foram considerados pelo historiador francês, Germain Bazin como pertencentes a uma escola: a Escola Franciscana do Nordeste. Este historiador ajudou a projetar o país como detentor de um patrimônio no campo da arte e arquitetura, trabalhando para o Instituto do Patrimônio Histórico e Artístico Nacional (IPHAN) por ocasião de sua fase chamada heroica, ou seja, nos seus primeiros trinta anos.

Para entender o trabalho e as colocações de Bazin quanto à ideia de chamar os conventos do Nordeste de "Escola", é necessário reportar-nos ao momento histórico do Brasil na época da criação do referido Instituto, que ocasionou a vinda ao Brasil de profissionais estrangeiros, entre eles, Germain Bazin.

\section{A Fundação do Instituto do Patrimônio Históri- co e Artístico Nacional - IPHAN}

As práticas de preservação do patrimônio cultural no Brasil, enquanto política pública, começam na década de 1920, com o Movimento Modernista. A partir da criação do Ministério da Educação e Saúde Pública, (1930) e a instauração do Estado Novo, em 1937, definiu-se preservar os bens do país, que resultou na criação do Serviço do Patrimônio Histórico e Artístico Nacional (SPHAN - hoje IPHAN). (COSTA, 1937).

Em fins de 1934, logo que assumiu o Ministério da Educação e Saúde, Gustavo Capanema solicita ao escritor modernista Mário de Andrade, para elaborar um anteprojeto objetivando a proteção à arte brasileira, isto é, a própria criação do SPHAN. 
Em abril de 1936 começou a funcionar o Serviço de proteção ao patrimônio, no âmbito provisório, e o arquiteto Lúcio Costa passou a fazer parte de seu quadro. Mário de Andrade representou a instituição em São Paulo (PINHEIRO, 2017). Em 1937, a ação provisória tomou caráter definitivo.

Para Mário de Andrade, que visava projetar o Brasil no quadro internacional, seu interesse voltou-se para a identidade nacional, onde o modernismo seria a corrente unificadora da brasilidade e da entidade nacional, referenciando a nação como uma realidade já consolidada.

Em seu anteprojeto constavam como metas, organizar, conservar e defender o patrimônio artístico nacional e, para promovê-lo, o IPHAN, deveria criar uma "Seção de Publicidade", divulgando os feitos realizados (CHUVA, 2009).

Entre novembro de 1935 e julho de 1937, os trabaIhos eram incipientes e direcionados aos consertos e manutenção dos bens "escolhidos" para serem preservados, por meio dos processos de tombamento (PINHEIRO, 2017).

Foi dessa forma, que o primeiro diretor do instituto, Rodrigo Melo Franco de Andrade (1936-1969), em comum acordo com seus funcionários, como Mário de Andrade, Lúcio Costa, Luís Saia e Edson Mota, definiram o que deveria ser o patrimônio brasileiro (URIBARREN, 2018), e as ações do órgão valori- zaram a construção de uma hierarquia dos bens, onde a arquitetura detinha a primazia, em relação a outras artes.

O Estado se tornou agenciador da memória da nação, e sob essa ótica deu-se a escolha dos bens a serem conservados. Essa prioridade de proteção, voltou-se aos representantes da arquitetura religiosa, e à arte colonial de modo geral, justificando-se pelo processo de urbanização em curso que colocava em risco o desaparecimento dessas obras (CALABRE, 2017). O Serviço também lutou juridicamente para realizar o tombamento de outros bens, inclusive os particulares.

A prioridade de tombamento aos bens da arquitetura religiosa era ainda justificada pelo seu próprio sentido. Para Lúcio Costa, a igreja, independente de seu esplendor, acolhia qualquer pessoa que quisesse usufruir do seu espaço, sem discriminação.

Mas, segundo Cunha (2010) houve também uma reação à incorporação dos estilos europeus promovida pelo ecletismo no Brasil e contra a desvalorização da arquitetura colonial, que alertava para a ameaça da perda dos monumentos nacionais. Assim, foi indiscutível a escolha do período colonial para fazer parte do patrimônio. Começaram, então, os processos de tombamento como medida de proteção aos bens.

As propostas de tombamento eram instruídas, sempre que possível, pelo histórico da obra, descrição, 
estado de conservação, alterações sofridas, referências bibliográficas e documentação fotográfica (CUNHA, 2010).

O tombamento se efetuava com a inscrição do bem selecionado em um ou mais Livros de Tombo, conforme a decisão do Diretor e/ou do Conselho Consultivo. Os Livros de Tombo seriam: Livro das Belas-Artes; Livro Histórico; Livro Arqueológico, Etnográfico e Paisagístico; e Livro das Artes Aplicadas, que não foi levado a termo.

As inscrições de tombamento no Livro do Tombo Histórico constituíam as séries históricas, levandose em conta a antiguidade do imóvel, mesmo que não detivesse importantes qualidades artísticas. Os bens religiosos são exemplos desses critérios.

Assim, o patrimônio constituiu-se pela arquitetura com isso a quantidade de tombamentos, efetuada somente durante o ano de 1938, foi significativa. Havia premência nos processos de tombamentos. Dessa forma, os arquitetos do SPHAN, pleno de direitos decisivos, sob a batuta de Rodrigo Meio Franco de Andrade, foram coautores da seleção dos bens tombados e definidores das características que compuseram nosso patrimônio.

A arquitetura daria materialidade à nação, e seria apresentada aos brasileiros pelo IPHAN. Os trabaIhos de seleção, depois dessa ânsia inicial, organizaram-se com regularidade (CHUVA, 2009).
Fundamental para a identificação e valorização do patrimônio foi a pesquisa histórica desenvolvida pelo órgão, propagada pelo diretor, que associava seus comentários às opiniões de "especialistas" nacionais e internacionais para colocar nossa arte no ambiente intelectual brasileiro e mundial, divulgando tais conhecimentos.

Foi um momento em que tradições necessitavam ser inventadas, edificando uma biografia da nação, que deveria lhe dar cunho histórico, munido de memória nacional.

Cabia ainda analisar sobre os personagens que podiam dar peso ao nosso patrimônio em âmbito nacional e internacional. Nacionalmente, Rodrigo Melo destacava a figura de Lúcio Costa, como sendo a maior autoridade da equipe e muitas vezes determinador das diretrizes relacionadas à seleção do patrimônio, com total apoio.

Percebe-se que as ações destinadas à proteção do patrimônio, que partiam do tombamento, foram oriundas de uma escolha, que priorizou alguns bens em detrimento de outros, por parte dos profissionais responsáveis por estas tarefas.

Segundo o Regimento Interno do IPHAN de 1946, tal atribuição não correspondia à divisão chefiada por Lúcio Costa, o que não o impediu de sempre dar a palavra final. (URIBARREN, 2015). 
Ampliando o leque das atividades do IPHAN, houve também a necessidade da presença no órgão de profissionais tais como fotógrafos, artistas plásticos, historiadores ou museólogos, alguns requisitados no exterior (URIBARREN, 2017).

Foi dessa forma que os profissionais estrangeiros contribuíram para a produção do conhecimento acerca do patrimônio brasileiro, especialmente na arquitetura. E assim, eles chegaram...

\section{Profissionais estrangeiros que colaboraram} com o IPHAN

Em 1937, Gustavo Capanema institui o Serviço de Cooperação Intelectual, a criação de bolsas no exterior para estudantes brasileiros, e subvenções às revistas e instituições que organizassem congressos internacionais sobre a cultura brasileira. Capanema queria inserir o Brasil no patrimônio cultural e intelectual da humanidade, além de promover estudos de história e literatura dos demais países do continente, inclusive nas universidades americanas.

Dessa forma, o norte-americano Robert Chester Smith (1912-1975), historiador e doutor pela universidade de Harvard, com tese sobre a arquitetura portuguesa, veio ao Brasil pela primeira vez em 1937, objetivando cooperar com a cultura internacional. Smith ainda esteve no Brasil em 1946 e em 1953.
Nessa missão, conheceu Rodrigo Melo, e estabelecendo-se uma simbiose, que representava, por parte do IPHAN, o acesso aos monumentos e arquivos brasileiros. Smith retribuía com palestras e publicações em revistas científicas estadunidenses.

Os pesquisadores americanos interessavam-se tanto pela arte colonial quanto pela arte moderna, deixando de lado a produção do século XIX e dos primórdios do século $X X$. Essa mesma orientação constava dos trabalhos do órgão e, sob essa ótica, esse era o momento para suprir a falha de estudos de história da arte e da arquitetura brasileiras, além do apoio à legitimação do nosso patrimônio. Era a hora de capacitar profissionais brasileiros e buscar a cooperação dos já "capacitados" estrangeiros (URIBARREN, 2018).

No momento em que Robert Smith chegou ao nosso país, os estudos sobre arte, arquitetura e urbanismo apenas começavam. Os acervos dos arquivos ainda eram desconhecidos e difíceis de serem reunidos, pois os trabalhos estavam dispersos, tornando a busca dificultosa. Foi assim que, amparado pela bagagem profissional, Smith iniciou suas pesquisas sobre arte, arquitetura e urbanismo no Brasil (SMITH, 2012).

Uma das características de sua linha era documentar/catalogar obras de arte e arquitetura do período colonial, trabalho realizado por ele nos Estados Unidos, Portugal e no Brasil. 
Smith utilizou documentos escritos para validar historicamente suas proposições, partindo de análises formais, ou seja, evidenciando tipos dentro de padrões ou estilos, na sequência cronológica. Sob essa visão, as descrições detalhadas das obras eram imprescindíveis, assim como as imagens, especificamente as fotografias, que ganharam destaque nas primeiras décadas do século XX (MELO, 2018). Seus trabalhos foram de grande importância na divulgação de nossa arte, e na organização utilizada pelo IPHAN como órgão preservador do patrimônio brasileiro.

E a interlocução com pesquisadores estrangeiros prossegue, resultando em mais estudos e publicações. É o caso de Hanna Levy (1912-1984), historiadora da arte alemã, que veio para o Brasil em 1937 por razões pessoais. Foi convidada por Rodrigo Melo para ministrar cursos de história da arte para funcionários da instituição, e dividiu sua vida profissional, entre o ensino e a pesquisa em história da arte (NAKAMUTA, 2009).

De acordo com o pensamento de Levy, a história deveria ser vista como um processo vinculado à história social, à conceituação de um dado momento da história da arte. Em seus artigos, levanta a questão de valores artísticos e históricos presentes de forma independente em uma obra, e acrescenta o valor da documentação, relacionado aos acontecimentos importantes da história.
Ao abordar a arte brasileira, livra-a de preconceitos, inclusive o eurocentrismo, ressaltando que a influência europeia não possuía significado de peso. Com essa posição, questiona a hierarquia de uma história da arte europeia sobre uma história da arte não europeia, quebrando estigmas sem perder 0 foco da obra e de seu contexto (BAUMGARTEN, 2013). Assim, foi mais uma defensora e propagadora, com seus estudos, da arte brasileira.

Já John Bury (1917), pesquisador inglês independente, esteve no Brasil entre 1947 e 1948. Enxergava a arquitetura brasileira no contexto internacional, porém diferente da interpretação nacionalista dada pelos modernistas. Manteve contato com o IPHAN em seus estudos sobre arquitetura e arte no Brasil colonial, voltando-se mais para as obras de Minas Gerais.

Estudou História Moderna na Universidade de Oxford entre 1935 e 1938. Ainda estudante, interessou-se pela arte barroca do Brasil e elegeu o Aleijadinho como assunto para sua tese, visitando as cidades históricas mineiras. Voltando à Inglaterra, ministrou palestras em universidades e publicou artigos sobre o barroco, chamando a atenção internacional para seu legado no Brasil, até então desconhecido no exterior e menosprezado em sua própria terra. 
Bury recebeu aval do IPHAN para elaboração de suas pesquisas relacionadas à arquitetura e às manifestações artísticas do Brasil, além da disponibilização de documentação e viagens a diferentes regiões do país. Retribuiu, com a divulgação de nossa arte.

Quanto a Germain Bazin (1901-1990), francês, historiador da arte e museólogo, nas suas viagens ao Brasil entre 1945 e 1949, também estabeleceu trocas com Rodrigo Melo e com os diretores regionais do órgão (MACHADO, 2017). Foi legitimador e difusor das ideias do IPHAN em nível mundial, observando as manifestações barrocas da arquitetura do Brasil (URIBARREN, 2018).

Teve apoio do governo da França para a sua primeira vinda ao Brasil, em 1945. Chegou para divulgar a cultura de seu país no contexto do pós-guerra. Essa viagem possibilitou rever seus interesses, observar e propagar a arte barroca, em um campo que estava praticamente virgem à espera de um historiador da arte. Não é preciso dizer o prazer que isso the proporcionou (PEREIRA, 2014). Bazin viria a ocupar um lugar de destaque no projeto de divulgação e validação do "barroco colonial" como expressão artística brasileira.

Datam da viagem de 1946 os primeiros sinais de acordo entre Bazin e o IPHAN para escrever dois livros sobre a produção barroca no Brasil, sendo um sobre arquitetura e outro sobre escultura, cul- minando na publicação dos livros "L'architecture religieuse baroque au Brésil" (1956) e "Aleijadinho et la sculpture baroque au Brésil” (1963).

Em outubro de 1949, Bazin voltou ao Brasil, a convite e patrocínio dos Diários Associados, representado por Assis Chateaubriand, que apresentou o historiador como sendo uma das maiores autoridades em arte religiosa no mundo (URIBARREN, 2018).

Seus trabalhos fortaleciam a estratégia de mostrar o empenho do IPHAN vinculado a nomes conhecidos internacionalmente, como o do próprio pesquisador francês. Em contrapartida, entendemos que Germain Bazin passou pelo Brasil mediado pelo IPHAN no plano das pesquisas, e de Assis Chateaubriand no que toca às finanças para suas publicações e viagens (URIBARREN, 2018).

Porém, no campo da arquitetura franciscana, não conseguimos precisar em que medida esse incentivo foi direcionado aos conventos do Nordeste, muito estudados pelo historiador, em detrimento dos conventos da mesma Ordem no Sudeste. Bazin se interessava pelo barroco, fato patente em suas obras. O Brasil dava seus primeiros passos a caminho desse estilo, principalmente nas fachadas dos conventos franciscanos da região Nordeste. Talvez, por esse motivo, faz-nos supor que tais conventos o tenham atraído mais. 
O interesse do IPHAN com a vinda dos estrangeiros era conhecer e fazer reconhecida internacionalmente a arte brasileira, legitimando a prática de preservação e de identificação desses bens por meio de levantamentos, pesquisas, estudos, discussões técnicas, publicações, exposições, cursos e conferências sobre a arte brasileira e sua divulgação no país e no exterior, com base nos diálogos que se faziam na historiografia da arte como, por exemplo, o barroco. Havia colaboração mútua entre os pesquisadores estrangeiros e o IPHAN (PEREIRA, 2014).

Contudo, havia lacunas documentais, novas perguntas e esclarecimentos que apareciam a todo instante. $E$ foi assim que questionamentos surgiram entre nós, sobre a obra de Bazin, especialmente no que diz respeito à chamada "Escola Franciscana do Nordeste".

Nem por isso, Bazin deixou de enaltecer a arquitetura brasileira como produto de uma civilização e deu ao barroco nacional um status de obra de arte, de expressão e de representação própria, diferenciando-o das manifestações desse estilo ocorridas em outros lugares, principalmente em Portugal (PEREIRA, 2014). Era tudo que o IPHAN precisava naquele momento

\section{A Fotografia e o IPHAN}

A dificuldade de acesso aos bens espalhados pelo nosso território, aliada à falta de verbas para o tra- balho de campo, fazia, em relação às fotografias, com que estas fossem usadas como fontes de consulta para os tombamento e obras de conservação e de restauração. Assim, a documentação fotográfica tornou-se importantíssima para as obras de restauração propostas pelo IPHAN, e como consulta por parte dos técnicos desta instituição. Já que na época não havia profissionais ligados à fotografia, e o acesso aos equipamentos fotográficos era escasso e oneroso, os profissionais estrangeiros desse campo, também estiveram ao encargo do IPHAN.

Em janeiro de 1948, Rodrigo Melo assinou uma Portaria intitulada "Fotografias de obras de valor artístico e histórico", que pretendia nortear as instruções a serem seguidas pelos técnicos e auxiliares destinados a fotografar monumentos e obras de arquitetura, pintura, escultura e arte aplicada, de valor histórico e artístico existentes no país, para elaborar os inventários. Tal fato gerou serviços prestados por fotógrafos estrangeiros ao IPHAN, na divulgação do conhecimento de arte e de história que o Brasil detinha, contribuindo para o seu estudo. Essa divulgação, conferia um caráter autenticador de um conhecimento propiciado pelo Estado, e muitos tombamentos eram baseados na análise fotográfica. Daí a importância da fotografia naquela época.

Em função da concentração dos bens, Rodrigo distribuía os locais onde os fotógrafos deveriam trabaIhar, principalmente onde havia um maior número de exemplares da arquitetura colonial. 
Em geral, os fprofissionais contratados iam a campo após a visita do técnico, que classificava os bens e solicitava as fotografias (LIMA, 2008).

Quanto aos fotógrafos estrangeiros que vieram para o Brasil para colaborar na formação dos arquivos do IPHAN, documentando as obras de arquitetura e artes, estes foram muitos, dos quais mencionaremos aqui alguns deles, dando continuidade ao histórico da criação do Órgão responsável pela preservação do nosso patrimônio cultural, em que as fotografias devem ser consideradas parte integrante deste.

Como, desde 1937, o fotógrafo alemão Eric Hess (1911-1995) passou a viajar pelo Brasil documentando bens de interesse para o patrimônio cultural, inclusive os monumentos que viriam a ser tombados posteriormente, ele atuou no IPHAN investido dessa função (GRIECO, 2016).

Viajou por todo o país sob os auspícios do SPHAN. Hess, contudo, não se atinha unicamente a pedidos oficiais. Identificava o que era necessário fotografar para organizar a documentação de um monumento.

Além da sua grande contribuição para os trabalhos de inventário fotográfico da arquitetura brasileira, pode-se destacar também a sua colaboração para a formação do acervo fotográfico do SPHAN (GRIECO, 2013).
Já Marcel Gautherot (1910-1996), fotógrafo francês, veio ao Brasil pela primeira vez em 1939. Construiu sua trajetória no ofício, ajudando a documentar, preservar o passado, e a registrar a ideia de uma nação moderna moldada naquela época.

Colaborou com o IPHAN desde 1940, unindo-se ao projeto de preservação da cultura nacional. Gautherot não apenas trabalhava para o IPHAN, como compartilhava a visão de que era necessário documentar todas as manifestações culturais que estavam se perdendo pelo caminho, além da arquitetura colonial.

Fazem parte ainda das fotografias do autor o tema sobre o barroco mineiro, que esteve na base da criação do IPHAN, como o conjunto das obras do Aleijadinho (MILLEN, 2017).

\section{Novamente Germain Bazin}

Como vimos, a vinda de Germain Bazin ao Brasil se tornou uma resposta positiva às necessidades do IPHAN, atendendo às expectativas na construção da historiografia da arte brasileira, especificamente à do período colonial.

No que se refere aos conventos franciscanos do Nordeste brasileiro, Bazin ao visitá-los na década de 1950, rotulou-os como pertencentes a uma Escola: a "Escola Franciscana do Nordeste", termo criado pelo historiador e consagrado por outros auto- 
res que dedicaram parte de seus trabalhos a esses mesmos cenóbios.

Ao rever os conventos referidos por Bazin como formadores dessa "escola", constatamos que o autor não explica em suas obras o porquê dessa denominação. Apenas cita algumas características pertinentes a esses conventos como sendo-lhes peculiares.

Verificamos por meio da literatura, que Bazin não deu o mesmo peso - ou não lhe foi solicitado - ao estudo dessa mesma arquitetura, na região Sudeste. Sabemos, a priori, que seu foco de interesse era o barroco, e as obras nacionais eram ainda virgens de pesquisas, possibilitando todo tipo de análise, principalmente das "autoridades" estrangeiras. Vale lembrar ainda que, no início da criação do IPHAN, as peças arquitetônicas que viriam a compor nosso patrimônio eram "escolhidas" pelos seus dirigentes. O interesse pelos conventos do Nordeste parecia falar mais alto, principalmente se considerarmos que as fachadas destes conventos eram mais providas de elementos barrocos que as fachadas do Sudeste. Assim, o interesse de Bazin poderia ter influenciado o IPHAN frente à priorização de tombamentos dos conventos franciscanos do Nordeste.

Dentre a vasta produção bibliográfica de Germain Bazin, o que efetivamente interessa a este estudo é a obra "L'Architecture religieuse coloniale au Bré- sil" (1956-58), versão brasileira "A Arquitetura Religiosa Barroca no Brasil"- 1983), tomada como base, em que o autor dedica uma parte de seu estudo à consagrada Escola Franciscana. O status de haver aqui em nosso solo uma Escola, dava ao Brasil uma importância maior. No entanto, também não são apontadas razões para tal denominação, senão suposições, com a recomendação de estudos posteriores, sobre uma oficina ambulante de construtores.

Da mesma forma, o IPHAN também não dedicou a mesma importância a todos os conventos franciscanos, tanto em seus processos de tombamentos, quanto ao arquivamento de documentações relacionadas às intervenções ocorridas neles. Melhor dizendo, houve quase um esquecimento em relação aos conventos do Sudeste, fato que pode ter propiciado a ruína e demolição de alguns exemplares desta região, além da descaracterização de outros. Isso veio a prejudicar bastante o estudo dessas construções, ainda mais se as quisermos comparar com os conventos do Nordeste.

Contudo, o que podemos tirar de concreto são as características consideradas por Bazin em relação aos conventos do Nordeste, para afirmar a existência da Escola por ele citada, reproduzidas a seguir.

- Quantidade, formato e localização dos claustros em relação à igreja principal - claustros únicos e, na maioria das vezes, à direita da igreja conventual; 
- Presença de adros com cruzeiros;

- Capela dos Terceiros - localizadas de forma perpendicular em relação ao conjunto conventual, comunicando-se com a igreja da Ordem Primeira através de um arco;

- Frontispícios das igrejas Primeiras, onde foram definidos dois tipos como modelo: o do Convento de Ipojuca e o do Convento de Cairu;

- Nave da igreja conventual - nave única;

- Torre - única, recuada em relação à fachada e na maioria das vezes, à esquerda da igreja conventual;

- Presença de Pórtico/Galilé - geralmente com três arcos.

Porém, em ambas as regiões essas características estão presentes, fazendo-nos questionar que, a afirmativa de Bazin, corroborada por outros autores, sobre a existência de uma "Escola Franciscana do Nordeste" pode ser problematizada a partir do estudo comparativo com relação ao Sudeste, principalmente se levarmos em conta a avidez que havia por parte da criação e divulgação de um patrimônio brasileiro, no contexto histórico da época do surgimento do órgão de proteção aos nossos bens culturais.

\section{Considerações Finais}

Pesquisadores de História da Arte brasileira vêm tentando buscar formas de construir um trabalho complementado com as fontes disponíveis. No entanto, não há um consenso que englobe autores que comunguem os mesmos pensamentos.

Há dificuldade de se buscar novas reflexões que ajudem a escrever a historiografia da arte no Brasil, uma vez que o debate crítico, começou ditado por uma visão estrangeira, não construindo oposições às ideias vigentes.

O discurso teórico e a produção artística incipiente no Brasil foram prejudicados por terem tido, apesar dos esforços, pouca divulgação e lacunas em relação aos estudos em outras partes do mundo. Isso tornou difícil para o pesquisador ter uma posição mais consistente.

Por isso, é premente construir uma historiografia da arte nacional que compreenda os caminhos percorridos, de acordo com cada época e comunidade cultural. Assim, o estudo das manifestações artísticas deve procurar um diálogo entre a imagem e o contexto social, lançando mão dos documentos disponíveis, mas encarando-o como mutável, mediante uma revisão historiográfica, que deve ser permanente. 
Quanto ao período colonial, é preciso que haja um novo olhar sobre os trabalhos realizados pela geração modernista, de caráter nacionalista, principalmente dos pesquisadores que atuaram nos primórdios do IPHAN. Além da ruptura com o passado, havia o compromisso com a questão nacional, necessidade basilar por época da criação do IPHAN. Os modernistas tiveram papel importante na ideia de preservação da memória, mas foram nesse sentido, doutrinadores.

Em relação a Bazin, pelas pesquisas e leitura de suas obras, parece ter acontecido o mesmo, no sentido de atender aos desejos da fase inicial da criação do IPHAN. Um capítulo de seu já citado livro "L'Architecture religieuse coloniale au Brésil", dedicado ao que o autor chamou de Escola Franciscana do Nordeste, não apresenta argumentação para assim batizar tais conventos que visitou quando prestava serviços ao IPHAN. Já os conventos do Sudeste foram poucos comentados neste livro, salvo exceções, talvez por não terem sido prioridades do órgão na época de sua fundação. Assim, Bazin também seguiu, tal qual os modernistas, o mesmo caminho de doutrinação e valorização da arte brasileira. Ainda assim, o historiador foi muito significante na disseminação da nossa arte em âmbito mundial.

No que diz respeito aos autores e trabalhos de uma geração mais recente, citados em um capítulo de minha tese (Alberto José de Sousa, Maria
Berthil de Moura Filha, José Dirson Argolo, Benedito Lima de Toledo, Maria Helena Matue Ochi Flexor, Geraldo Gomes da Silva), podemos constatar que todos são unânimes em mencionar o termo Escola Franciscana do Nordeste, utilizado por Germain Bazin. Porém, também estes autores não se posicionam quanto à explicação pelo uso da mesma terminologia lançada por Bazin.

A bibliografia não é clara quanto à definição de "Escola". Tal conceito aparece descrito segundo a ótica da História e Filosofia, o que não nos parece ser o que Bazin aplicou para determinar a existência de uma "Escola Franciscana do Nordeste". Talvez Bazin tenha pretendido fazer uso dos critérios que correspondem à definição de Estilo, indicando um grupo de características mais ou menos constantes, que permitem a identificação da arte produzida em um período histórico, em uma região, por um grupo de artistas, ou de um único artista, relacionando uma obra à sua origem. Ainda assim, Estilo é um conceito da história da arte de significado amplo e vago.

Contudo, a historiografia não é definitiva; é dinâmica. E, por isso, exige um debate contínuo e a constante busca de explicações para aquele momento em que se escreve a História, sendo primordial observar leituras produzidas pelas gerações predecessoras, até mesmo para sedimentar novas ideias, principalmente se os temas já são consagrados e tidos como sacramentados. Foi o que foi feito neste 
trabalho, no qual esperamos ter deixado a nossa cota de contribuição, sem que venha a ser mais uma "verdade absoluta", mas com a certeza de ter "aguçado" um questionamento inédito, que poderá nortear novos pesquisadores.

\section{Referências:}

BAUMGARTEN, Jens; TAVARES, André. O Barroco colonizador: a produção historiográfico-artística no Brasil e suas principais orientações teóricas. Perspective. Actualité en histoire de l'art, n. 2, 2013.

Disponível

em:

<https://journais.openedition.org/perspective/5538>. Acesso em: 14/09/2018.

CALABRE, Lia. O Serviço do Patrimônio Artístico Nacional dentro do contexto da construção das políticas públicas de cultura no Brasil, Revista do Patrimônio Histórico e Artístico Nacional, $n^{\circ} 35$, 2017.

CHUVA, Márcia Regina Romeiro. Os Arquitetos da Memória: sociogênese das práticas de preservação do patrimônio cultural no Brasil (anos 19301940). Rio de Janeiro: UFRJ, 2009.

COSTA, Lúcio. Documentação necessária. Revista do patrimônio histórico e artístico nacional, n. 1, 1937.

CUNHA, Cláudia dos Reis e. Restauração: diálogos entre teoria e prática no Brasil nas experiências do IPHAN. Tese (Doutorado em arquitetura e urbanismo) - Faculdade de arquitetura e urbanismo, Universidade de São Paulo, São Paulo, 2010. 
GRIECO, Bettina Zellner. Entrevista com Erich Joachim Hess Memórias do patrimônio 3. Rio de Janeiro: IPHAN, 2013.

ERICH HESS: fotografia e patrimônio. Fórum Patrimônio: Ambiente Construído e $\mathrm{Pa}$ trimônio Sustentável, v. 9, n. 1, 2016.

LIMA, Francisca Helena Barbosa; MELHEM, Mônica Muniz; BRITO E CUNHA, Oscar Henrique Liberal. A fotografia na preservação do patrimônio cultural: uma abordagem preliminar. Cadernos de pesquisa e documentação do IPHAN, v. 4, 2008.

MACHADO, Jurema. Feito em casa: o Iphan e a cooperação internacional para o patrimônio. Revista do Patrimônio Histórico e Artístico Nacional, Brasília, n. 35, 2017.

MELO, Sabrina Fernandes. Robert Chester Smith e os estudos das cidades coloniais. URBANA: Revista Eletrônica do Centro Interdisciplinar de Estudos sobre a Cidade, v. 10, n. 1, 2018.

MILLEN, Mánya. Por dentro dos acervos - O Brasil de Gautherot, Rio de Janeiro, Instituto Moreira Salles, 12 de junho 2017. Disponível em: <https://ims.com.br/por-dentro-acervos/obrasil-de-gautherot/>. Acesso em: 12 de dezembro de 2018
NAKAMUTA, Adriana. Hanna Levy no SPHAN (1946-1948). Arquivos do IPHAN, revista eletrônica de pesquisa e documentação, Rio de Janeiro, dezembro de 2009. Disponivel em: $<$ http://portal.iphan.gov.br/uploads/publicacao/SerPe sDoc5_HannaLevySPHAN_m.pdf>. Acesso em: 23/06/2018.

PEREIRA, Cecilia Ribeiro. Robert Smith, diálogos e pesquisas no Brasil. Cadernos de Arquitetura e Urbanismo, v. 21, n. 28, p. 86-99, 2014. Disponível em:

$<$ http://periodicos.pucminas.br/index.php/Arquitetura eurbanismo/article/viewFile/P.2316-

1752.2014v21n28p86/7851>. Acesso em: 23/06/2018.

PINHEIRO, Maria Lucia Bressan. Trajetória das ideias preservacionistas no Brasil: as décadas de 1920 e 1930. Revista do Patrimônio Histórico e Artístico Nacional, n. 35, 2017.

SMITH, Robert Chester. Robert Smith e o Brasil: arquitetura e urbanismo / Robert Chester Smith; organização, Nestor Goulart Reis Filho; tradução Patrícia Zimbres. -- Brasília, DF: Iphan, 2012.

URIBARREN, Maria Sabina. Contatos e intercâmbios americanos no IPHAN: o Setor de Recuperação de Obras de Arte (1947-1976). Tese (Douto 
rado em Arquitetura e urbanismo) - Faculdade de Arquitetura e Urbanismo, Universidade de São Paulo, São Paulo, 2015.

Pintores no Instituto do Patrimônio Histórico e Artístico Nacional: a preservação dos "bens móveis e integrados" no Brasil entre 1937 e 1976. CAIANA, v. 11, 2017.
Germain Bazin e o IPHAN. Revista CPC,

v. 13, n. 25 esp, 2018. 